\title{
An Analysis of International Sociolinguistics Research: Based on Web of Science from 2010 to 2016
}

\author{
Xue $\mathrm{Yu}^{1, \mathrm{a}}$ and Shili $\mathrm{Ge}^{1,2, \mathrm{~b}^{*}}$ \\ ${ }^{1}$ School of English for International Business, Guangdong University of Foreign Studies, \\ Guangzhou, China \\ ${ }^{2}$ Guangdong Collaborative Innovation Center for Language Research \& Service, Guangdong \\ University of Foreign Studies, Guangzhou, China \\ a20150310037@gdufs.edu.cn, bgeshili@gdufs.edu.cn
}

Keywords: CiteSpace, Sociolinguistics, Knowledge Mapping.

\begin{abstract}
Sociolinguistics is the study of the interaction between language and society. In order to explore the status quo of the international sociolinguistics study, we collected 459 articles with 19414 references from Web of Science (WoS), retrieved on March 15, 2017. With the help of CiteSpace, knowledge maps of author co-citation, keywords clusters and document co-citation were created. Top 30 most cited authors, 8 keywords clusters and top 10 most co-cited documents are analyzed. The analysis of related research documents reveals the overall research trend in sociolinguistics study in recent years.
\end{abstract}

\section{Introduction}

The study of sociolinguistics has developed rapidly in recent years and has a significant impact on social life due to the close relationship between language and society. It is "a way of viewing the world around you" [1]. For the interdisciplinary foundation and diverse application areas, sociolinguistics encompasses numerous research topics and subfields. In recent years, CiteSpace has been found wide application and obvious effect. It is necessary to analyze the data of sociolinguistics with this effective tool. To our knowledge, there is no existing literature which adopts CiteSpace to analyze sociolinguistics yet. The application of this new tool reveals the complex relations between authors, hot topics and even social structure.

\section{Visualization study of research documents}

CiteSpace is particularly designed to support the data input, data output and analytic process. Since images contain much more information than words, tables or even graphs, the relationship between authors and cited references can be displayed clearly. Because of the high efficiency of data processing and image generating, CiteSpace has been applied to numerous areas for research documents study.

Wang and $\mathrm{Li}$ [2] carried out a CiteSpace-based survey of international advances in business English research. With the CiteSpace technology, the hot areas of study and the most influential theories in business English studies were found out. CiteSpace was also used to detect hot topics and fronts in international higher education research [3], analyze research fronts of international technological innovation [4] and so on.

\section{Research Questions}

This paper focuses on three issues:

1)Which authors have the greatest impact on sociolinguistic research?

2) What are the hot topics of sociolinguistic research? and

3) What are the research fronts of sociolinguistic research? 


\section{Results and Discussion}

4.1 Mapping of Author Co-citation Analysis The author's academic influence can be measured by the frequency of citations, which is an objective and practical indicator of the extent to which the author's articles are used and valued, as well as their status in the field. Citation frequency is a form of peer cognition, which reflects the academic community's trust and recognition for scholars. On the other hand, it also reflects the contribution and influence of scholars to the development of the subject, and even can be said that highly cited authors forming the core of a scientific research group [5]. Author co-citation analysis is a set of data gathering, analyzing, and graphic displaying techniques that can be used to produce empirical maps of prominent authors in various areas of scholarship [6].

In CiteSpace, we select "Noun Phrases" as "Term Type", "Cited Author " as "Node Types", and keep other parameters unchanged. After collating the data, we can get the first 30 authors who have great impact on sociolinguistic research in Table 1.

Labov William, an American linguist, widely regarded as the founder of the discipline of variationist sociolinguistics. He has been described as "an enormously original and influential figure who has created much of the methodology" of sociolinguistics. According to our results, Labov William was the most cited author. His work is cited by the articles in the database (210 times) and undoubtedly has a huge impact on other authors.

Table 1. Top 30 most cited authors in the field of Sociolinguistics.

\begin{tabular}{|c|c|c|c|c|c|}
\hline No. & Author & Counts & No. & Author & Counts \\
\hline 1 & Labov William & 210 & 16 & Milroy Lesley & 46 \\
\hline 2 & Blommaert Jan & 117 & 17 & Tagliamonte Sali & 44 \\
\hline 3 & Eckert Penelope & 106 & 18 & Cameron Deborah & 42 \\
\hline \multicolumn{3}{|c|}{ Silverstein } & \multicolumn{3}{|c|}{ Androutsopoulos } \\
\hline 4 & Michael & 97 & 19 & Jannis & 41 \\
\hline \multicolumn{6}{|c|}{ Coupland } \\
\hline 5 & Nikolas & 87 & 20 & Poplack Shana & 41 \\
\hline 6 & Rampton Ben & 66 & 21 & Agha Asif & 39 \\
\hline 7 & Trudgill Peter & 65 & 22 & Bakhtin Mikhail & 36 \\
\hline 8 & Bucholtz Mary & 63 & 23 & Gal Susan & 34 \\
\hline 9 & Bourdieu Pierre & 62 & 24 & Eckert Penelope & 33 \\
\hline 10 & Heller Monica & 59 & 25 & Holmes Janet & 33 \\
\hline 11 & Gumperz J J & 56 & 26 & Johnstone B & 31 \\
\hline 12 & Goffman Erving & 55 & 27 & Silverstein Michael & 31 \\
\hline 13 & Bauman R & 47 & 28 & Pennycook Alastair & 31 \\
\hline \multicolumn{6}{|c|}{ Fairclough } \\
\hline 14 & Norman & 47 & 29 & Hymes Dell & 26 \\
\hline 15 & Bell A & 46 & 30 & Ochs E & 23 \\
\hline
\end{tabular}

4.2 Keywords Clusters in International Sociolinguistics For clustering, the following parameters were adopted: Term Source $=$ Title / Abstract / Author Keyword (DE) / Keyword Plus (ID); Term Type $=$ Noun Phrase; Node Type $=$ Keyword $/$ Term .

CiteSpace provides two values of modularity ( $Q$ value) and average silhouette value (S value) according to the structure of network and the clarity of clustering, which can be used as the basis for evaluating the effect of mapping. With Modularity Q value of 0.4668 and the Silhouette of 0.5545 , we can get a satisfactory partition of network. Cluster 9 and 10 with silhouette 0 are ignored. The label of keywords clusters represent the hot topics in sociolinguistic research. 
Table 2. Details of knowledge clusters.

\begin{tabular}{ccccl}
\hline ID & Size & Silhouette & Label & \multicolumn{2}{c}{ Typical Collocation } \\
\hline 0 & 38 & 0.568 & gender & $\begin{array}{l}\text { language and gender(6), } \\
\text { grammatical gender(5) }\end{array}$ \\
\hline 1 & 33 & 0.568 & bilingualism & bilingualism(28) \\
\hline 2 & 31 & 0.543 & design & $\begin{array}{l}\text { audience design(6), } \\
\text { design(6) }\end{array}$ \\
\hline 3 & 26 & 0.64 & humor & humor(5) \\
\hline 4 & 22 & 0.538 & $\begin{array}{c}\text { language } \\
\text { contact }\end{array}$ & language contact(31) \\
\hline 5 & 17 & 0.765 & style & speech style(11), style shifting(5) \\
\hline 6 & 17 & 0.676 & enregisterment & digital enregisterment(2) \\
\hline 7 & 8 & 0.854 & japanese & Japanese women(5) \\
\hline 8 & 7 & 0.949 & information & $\begin{array}{l}\text { information } \\
\text { conceptual information(3) }\end{array}$ \\
\hline
\end{tabular}

In order to better understand the labels, we searched the label words in the corpus of source documents with self-coded Python programs to find the lexical collocation. The first one or two collocations in the results are in listed in the last column of Table 4. The number in the bracket is the frequency of the phrase or the word.

4.3 Mapping of Document Co-Citation Analysis. The "Node Type" was changed to "Cited Reference". After running CiteSpace, brief information such as the author name and publication year of the top 10 co-cited document can be found. We show the information in Table 3 according to the results from CiteSpace. In all the references, the book written by Blommaert is cited most. Another three articles of Blommaert's are also listed in the top 10. The pivotal points that usually put the major theoretical or innovative concepts in document co-citation network can represent the research front. These documents listed in Table 3 can be regarded as the research fronts of international sociolinguistics study.

Table 3. Most frequently cited reference ranked by citation counts.

\begin{tabular}{|c|c|c|c|c|}
\hline No. & Author & Year & Articles/Books & Counts \\
\hline 1 & Jan Blommaert & 2010 & $\begin{array}{c}\text { The Sociolinguistics of } \\
\text { Globalization }\end{array}$ & 43 \\
\hline 2 & Penelope Eckert & 2008 & $\begin{array}{l}\text { Variation and the indexical } \\
\text { field }\end{array}$ & 30 \\
\hline 3 & $\begin{array}{l}\text { Nikolas } \\
\text { Coupland } \\
\end{array}$ & 2007 & $\begin{array}{c}\text { Style: Language Variation } \\
\text { and Identity }\end{array}$ & 24 \\
\hline 4 & Asif Agha & 2007 & $\begin{array}{c}\text { Language and Social } \\
\text { Relations }\end{array}$ & 19 \\
\hline 5 & Jan Blommaert & 2011 & Language and superdiversity & 13 \\
\hline 6 & Jan Blommaert & 2005 & $\begin{array}{l}\text { Discourse: A Critical } \\
\text { Introduction }\end{array}$ & 13 \\
\hline 7 & Daniel Johnson & 2009 & $\begin{array}{c}\text { Getting off the } \\
\text { GoldVarb Standard: } \\
\text { Introducing Rbrul for } \\
\text { Mixed-Effects Variable Rule } \\
\text { Analysis } \\
\end{array}$ & 12 \\
\hline 8 & Mary Bucholtz & 2005 & $\begin{array}{c}\text { Identity and interaction: a } \\
\text { sociocultural linguistic } \\
\text { approach } \\
\end{array}$ & 12 \\
\hline 9 & Jan Blommaert & 2005 & Spaces of multilingualism & 12 \\
\hline 10 & Pennycook Alastair & 2007 & $\begin{array}{c}\text { Global Englishes and } \\
\text { Transcultural Flows } \\
\end{array}$ & 11 \\
\hline
\end{tabular}




\section{Summary}

In this paper, the visual analysis of the international sociolinguistic research based on Web of Science objectively reveals the trend of international sociolinguistics in the past seven years. According to the knowledge maps generated by CiteSpace, keywords clusters which represent the hot topics, and the most influential authors and documents which depict the research front are clearly presented.

There are some limitations of this paper. Author co-citation analysis studies are limited to the first author of a cited reference only. The interpretation step is the weakest link. It is time-consuming and cognitively demanding, requiring a substantial level of domain knowledge and synthesizing skills [7]. And the author has limited access to the data in the core data collection of Web of Science, so only the data from 2010 to 2016 are processed and the data analysis result is not comprehensive. Future research should be conducted based on larger dataset to reveal the overall trend of sociolinguistic study.

\section{Acknowledgements}

This research was supported by Higher Education Reform Project of Guangdong Province (GDJG20141094) and Graduate Education Innovation Plan of Guangdong Province (2015JGXM-MS22).

\section{References}

[1] R. Wardhaugh and J. Fuller, An Introduction to Sociolinguistics, Willey Blackwell, New Jersey, pp. 1-24, 2015.

[2] W. L. Fei and L.Lin, CiteSpace-based Survey of International Advances in Business English Research (2002-2012), Foreign Languages in China, vol. 11, pp. 88-96, 2014.

[3] P. Li and H. J. Hua, Hot Topics and Fronts of International Higher Education Research-Based on Analysis of Document Co-citation of 8 International Higher Education Journals from SSCI during 2000-2011, Educational Research, vol. 6, pp. 136-143, 2012.

[4] X. Z. Liang and G. X. Chuan, The Evolution Course of the Research Fronts of International Technological Innovation in Fifty Years-Based on view of Scientific Knowledge Mapping, Studies in Science of Science, vol. 30, pp. 44-59, 2012.

[5] L. H. Man, The Cuttiing-edge Research Interests and Topics of International Translation Studies: A Visualized Analysis of Relevant SSCI Data (2008-2012), Chinese Translators Journal, vol. 2, pp. 21-26, 2014.

[6] M. W. Katherine, Mapping Authors in Intellectual Space: A Technical Overview, Journal of the American Society for Information Science, vol. 41, pp. 433-443, 1990.

[7] C. C. Mei, I. Fidelia and H. J. Hua, The Structure and Dynamics of Co-citation Clusters: A Multiple-Perspective Co-Citation Analysis, Journal of the American Society for Information Science and Technology, vol. 61, pp. 1386-1409, 2010. 